\title{
Neural predictors of chocolate intake following chocolate exposure
}

Citation for published version (APA):

Frankort, A., Roefs, A., Siep, N., Roebroeck, A., Havermans, R., \& Jansen, A. (2015). Neural predictors of chocolate intake following chocolate exposure. Appetite, 87, 98-107.

https://doi.org/10.1016/j.appet.2014.12.204

Document status and date:

Published: 01/04/2015

DOI:

10.1016/j.appet.2014.12.204

Document Version:

Publisher's PDF, also known as Version of record

Document license:

Taverne

Please check the document version of this publication:

- A submitted manuscript is the version of the article upon submission and before peer-review. There can be important differences between the submitted version and the official published version of record.

People interested in the research are advised to contact the author for the final version of the publication, or visit the DOI to the publisher's website.

- The final author version and the galley proof are versions of the publication after peer review.

- The final published version features the final layout of the paper including the volume, issue and page numbers.

Link to publication

\footnotetext{
General rights rights.

- You may freely distribute the URL identifying the publication in the public portal. please follow below link for the End User Agreement:

www.umlib.nl/taverne-license

Take down policy

If you believe that this document breaches copyright please contact us at:

repository@maastrichtuniversity.nl

providing details and we will investigate your claim.
}

Copyright and moral rights for the publications made accessible in the public portal are retained by the authors and/or other copyright owners and it is a condition of accessing publications that users recognise and abide by the legal requirements associated with these

- Users may download and print one copy of any publication from the public portal for the purpose of private study or research.

- You may not further distribute the material or use it for any profit-making activity or commercial gain

If the publication is distributed under the terms of Article $25 \mathrm{fa}$ of the Dutch Copyright Act, indicated by the "Taverne" license above, 
Research report

\title{
Neural predictors of chocolate intake following chocolate exposure
}

\author{
Astrid Frankort ${ }^{\mathrm{a}}$, Anne Roefs ${ }^{\mathrm{a}, *}$, Nicolette Siep ${ }^{\mathrm{a}}$, Alard Roebroeck ${ }^{\mathrm{b}}$, Remco Havermans ${ }^{\mathrm{a}}$, \\ Anita Jansen ${ }^{\mathrm{a}}$ \\ a Department of Clinical Psychological Science, Faculty of Psychology and Neuroscience, Maastricht University, P.O. Box 616, Maastricht 6200 MD, The \\ Netherlands \\ ${ }^{\mathrm{b}}$ Department of Cognitive Neuroscience, Faculty of Psychology and Neuroscience, Maastricht University, The Netherlands
}

\section{A R T I C L E I N F O}

\section{Article history:}

Received 15 July 2014

Received in revised form 23 November

2014

Accepted 13 December 2014

Available online 17 December 2014

\section{Keywords:}

Brain-as-predictor

Cue reactivity

fMRI

Food craving

Food reward

\begin{abstract}
A B S T R A C T
Previous studies have shown that one's brain response to high-calorie food cues can predict long-term weight gain or weight loss. The neural correlates that predict food intake in the short term have, however, hardly been investigated. This study examined which brain regions' activation predicts chocolate intake after participants had been either exposed to real chocolate or to control stimuli during approximately one hour, with interruptions for fMRI measurements. Further we investigated whether the variance in chocolate intake could be better explained by activated brain regions than by self-reported craving. In total, five brain regions correlated with subsequent chocolate intake. The activation of two reward regions (the right caudate and the left frontopolar cortex) correlated positively with intake in the exposure group. The activation of two regions associated with cognitive control (the left dorsolateral and left middorsolateral PFC) correlated negatively with intake in the control group. When the regression analysis was conducted with the exposure and the control group together, an additional region's activation (the right anterior PFC) correlated positively with chocolate intake. In all analyses, the intake variance explained by neural correlates was above and beyond the variance explained by self-reported craving. These results are in line with neuroimaging research showing that brain responses are a better predictor of subsequent intake than self-reported craving. Therefore, our findings might provide for a missing link by associating brain activation, previously shown to predict weight change, with short-term intake.
\end{abstract}

(C) 2014 Elsevier Ltd. All rights reserved.

\section{Introduction}

Self-reports of attitudes and intentions rely on introspection, and it is well known that people do not have introspective access to all causes that underlie their behaviour (Nisbett \& Wilson, 1977) and that these self-reports can be distorted by socially desirable answering tendencies (Schwarz \& Oyserman, 2001). Recently, neuroimaging research showed that brain responses have added value in the prediction of behaviour. For example, in participants who were exposed to persuasive messages regarding the value of regular sunscreen use or the benefits of quitting smoking, brain activation was a better predictor of subsequent behaviour than were

Abbreviations: CERP, cue exposure with response prevention; PFC, prefrontal cortex; BMI, body mass index; VAS, visual analogue scale; OFC, orbitofrontal cortex; ROI, region of interest.

Acknowledgements: We would like to thank Ing. Charlie Bonnemayer of Maastricht University for programming parts of the stimulus protocol in E-Prime, as well as Dr. Armin Heinecke of Brain Innovation B.V. for his help with the data analysis. This work was supported by the Netherlands Organisation for Scientific Research (NWO) (grant number 400.06.148 to A.J.).

* Corresponding author.

E-mail address: a.roefs@maastrichtuniversity.nl (A. Roefs). self-reports of intentions (Falk, Berkman, Mann, Harrison, \& Lieberman, 2010; Falk, Berkman, Whalen, \& Lieberman, 2011). Likewise, in addicted participants, the brain response to pictures or videos of cues of the particular drug was a better predictor for relapse than were subjective craving reports (Grüsser et al., 2004; Kosten et al., 2006). Studies investigating the neural responsivity to highcalorie food cues also found that this activation in brain reward regions was correlated with weight gain after one year (Stice, Yokum, Bohon, Marti, \& Smolen, 2010; Yokum, Ng, \& Stice, 2011) or with less success in losing weight in a subsequent weight-loss program (Murdaugh, Cox, Cook, \& Weller, 2012). Further, long-term weight gain was negatively correlated with activation of regions involved in the inhibition of food reward (Kishinevsky et al., 2012; Stoeckel, Murdaugh, Cox, Cook, \& Weller, 2013).

Although many studies in the last few years have investigated the differences between healthy-weight and overweight people with regard to neural correlates of food reward (e.g., Batterink, Yokum, \& Stice, 2010; Frankort et al., 2012; Rothemund et al., 2007; Stoeckel et al., 2008), the neural correlates in response to visual food cues or taste cues that predict subsequent food intake or food choice in the short term have so far been studied only recently (Hare, Malmaud, \& Rangel, 2011; Lawrence, Hinton, Parkinson, \& Lawrence, 2012; Mehta et al., 2012; Spetter, de Graaf, Viergever, \& Smeets, 2012; 
Van der Laan, De Ridder, Viergever, \& Smeets, 2012). The study by Lawrence et al. (2012) for example found that snack consumption after the scanning session was predicted by activation of the nucleus accumbens in response to food cues. Prediction of the amount of food intake is interesting because weight gain is ultimately the result of a sustained positive energy balance, that is, total energy intake minus total energy expenditure (Swinburn et al., 2009). The goal of the current study was to examine whether neural correlates of food reward and inhibition could predict food intake during an alleged taste-test. The predictive validity of these neural correlates was studied under two conditions: during a session of exposure to the smell of chocolate without eating and during a control exposure (no food). Neural responses to chocolate pictures versus neutral pictures were measured using functional magnetic resonance imaging (fMRI).

Prolonged exposure is a well-known treatment strategy in the clinical practice of mental health care. During food cue exposure with response prevention (CERP), one is exposed to food cues, like the smell or taste of foods, or contexts, like eating places, that predict food intake, while at the same time eating is not allowed (response prevention). In bulimia nervosa and binge eating patients, as well as in obese children, CERP has been shown to be effective in reducing the urge to binge or the frequency of bingeing (Boutelle et al., 2011; Jansen, Broekmate, \& Heymans, 1992; Kennedy, Katz, Neitzert, Ralevski, \& Mendlowitz, 1995; Martinez-Mallén et al., 2007; Toro et al., 2003). The exposure aims to disrupt the conditioned link between the food cue (sight, smell or context of food intake) and one's learned response to this cue (eating). Actually, during repeated prolonged effective exposure it is learned that the food cue or context does not predict intake anymore (see e.g., Jansen, Havermans, \& Nederkoorn, 2011). During the exposure which ranged from $45 \mathrm{~min}$ to $90 \mathrm{~min}$ in the different studies, levels of self-reported craving first increased during prolonged exposure, peaked and then slowly decreased to the end. After several sessions (ranging from 1 to 36 sessions), the self-reported craving and/or physiological indices of craving did not go up anymore and almost fully extinguished (see, e.g., Jansen, Van den Hout, De Loof, Zandbergen, \& Griez, 1989; Jansen et al., 1992; Martinez-Mallén et al., 2007; Toro et al., 2003; Van Gucht et al., 2008). In our lab, we measured the effect of prolonged exposure to the smell of chocolate, without eating, on self-reported cravings and brain responses to neutral and chocolate pictures (Frankort et al., 2013). It was found that self-reported chocolate craving in a group that was exposed to chocolate increased over a one-hour session, reaching a peak just before the end of the session, followed by a tendency towards a decrease (for a graph of craving over time, please see Frankort et al., 2013). Contrary to expectations, chocolate cravings did not extinguish within the hour. However, activation in brain reward regions in response to chocolate versus neutral pictures rose from the start to the middle of the session. At the end of the session the brain reward activation returned to control levels again, indicating that craving on a neural level did extinguish. Therefore, brain reward activation was considered to be a precursor of self-reported craving (Frankort et al., 2013).

The current study follows up on these results and focuses specifically on chocolate intake during a bogus taste-test that was performed after the fMRI scanning session. We expected that chocolate exposure would lead to reduced intake as compared to the neutral control exposure, because a prolonged exposure usually leads to a decrease in craving. Further it was expected that brain activation in response to chocolate versus neutral pictures in regions associated with food reward would show predictive validity with regard to subsequent intake above and beyond the variance explained by self-reported craving. Brain regions commonly accepted to be involved in food reward are the amygdala, striatum, hippocampus, insula, ventral tegmental area and substantia nigra, as well as the anterior cingulate, posterior fusiform, orbitofrontal and prefrontal cortices (for reviews see: Berridge, Ho, Richard, \& DiFeliceantonio, 2010; Berthoud, Lenard, \& Shin, 2011; Carnell, Gibson, Benson, Ochner, \& Geliebter, 2012; Kringelbach, 2009; Rolls, 2011; Small, 2009; Smeets, Charbonnier, Van Meer, Van der Laan, \& Spetter, 2012; Van der Laan, De Ridder, Viergever, \& Smeets, 2011). Regions that appear to be involved in the inhibition of food reward, in the sense that less activation in a delay discounting task or a lower grey matter volume of these regions predicted more long-term weight gain in women, are subdivisions of the prefrontal cortex (PFC) like ventrolateral, dorsolateral and medial PFC, as well as posterior parietal cortex (Kishinevsky et al., 2012; Stoeckel et al., 2013; Yokum, Ng, \& Stice, 2012). More specifically, because previous papers found that brain activation was a better predictor of behaviour than were self-reports (Falk et al., 2010, 2011; Grüsser et al., 2004; Kosten et al., 2006), we expect activation in these regions to explain variance in chocolate intake (as measured directly after the scanning session), on top of what is predicted by self-reported craving.

\section{Method}

Part of these data have been published in a previous paper (Frankort et al., 2013), which focused on the course of brain activation during the cue exposure session. In contrast, the current paper investigates the prediction of short-term chocolate intake after the session by brain activation.

\section{Participants}

34 female undergraduate students of Caucasian ethnicity from Maastricht University participated with full informed consent: 17 in an exposure group and 17 in a control group. They were righthanded, not currently on a weight-loss diet and had a low score (total score $<14$ ) on the Restraint Scale (Herman \& Polivy, 1980). Exclusion criteria were a self-reported mental disorder history or family history of eating disorders. Both groups had similar age and scores of hunger, restraint and trait chocolate craving, but body mass index (BMI) tended to differ between the groups (see Table 1 for participant characteristics). Seven additional participants were excluded from analyses due to scanner problems or excessive head movement. Participation was remunerated with $€ 30$ or course credits. The local ethical committee approved the study.

\section{Assessment}

\section{Self-reported chocolate craving}

Self-reported chocolate craving was measured repeatedly with a visual analogue scale (VAS) item asking "how much do you crave chocolate at this moment", ranging from 0 (not at all) to 100 (very much).

\section{Trait chocolate craving}

To assess the trait craving for chocolate and the degree of compulsive behaviour elicited by chocolate, the craving subscale of the Attitudes to Chocolate Questionnaire (Benton, Greenfield, \& Morgan, 1998) was used. All items addressed preoccupation with chocolate, with the scale for each item ranging from 0 (this does not apply to me at all) to 100 (this very much applies to me). The subscale is considered valid and reliable (Cramer \& Hartleib, 2001; Müller, Dettmer, \& Macht, 2008). The total score was computed by averaging the ten VAS items (0 to 100).

\section{Hunger}

A VAS item asking "How hungry do you feel at this moment?", ranging from 0 (not hungry at all) to 100 (very hungry), was used to assess hunger. 
Table 1

Characteristics and self-report data of participants.

\begin{tabular}{|c|c|c|c|c|c|c|}
\hline & \multicolumn{2}{|c|}{$\begin{array}{l}\text { Exposure group } \\
(n=17)\end{array}$} & \multicolumn{2}{|c|}{$\begin{array}{l}\text { Control group } \\
(n=17)\end{array}$} & \multirow[b]{2}{*}{$t(32)$} & \multirow[b]{2}{*}{$p$} \\
\hline & M & SD & M & SD & & \\
\hline Age (yrs) & 19.8 & 1.4 & 20.2 & 1.5 & .89 & .38 \\
\hline BMI & 22.8 & 1.7 & 21.6 & 1.8 & 1.94 & .06 \\
\hline Time between lunch and scan ( $\mathrm{min}$ ) & 86.5 & 14.4 & 82.6 & 20.9 & .62 & .54 \\
\hline Hunger $^{\mathrm{a}}$ & 18.6 & 14.5 & 14.9 & 14.1 & .74 & .46 \\
\hline Restraint $^{\mathrm{b}}$ & 10.6 & 2.6 & 10.8 & 4.7 & .18 & .86 \\
\hline Trait chocolate craving ${ }^{\mathrm{c}}$ & 38.3 & 19.1 & 35.0 & 13.2 & .58 & .56 \\
\hline Overall chocolate intake (g) & 19.6 & 15.8 & 24.7 & 16.4 & .92 & .36 \\
\hline Overall chocolate intake (kcal) & 108.8 & 88.3 & 136.7 & 91.3 & .91 & .37 \\
\hline
\end{tabular}

Note: Reprinted with permission from Frankort et al. (2013) Cerebral Cortex.

Abbreviations. $\mathrm{BMI}=$ Body Mass Index.

a Scored on $100 \mathrm{~mm}$ VAS, ranging from 0 (not hungry at all) to 100 (very hungry).

b Scored on the Restraint Scale (Herman \& Polivy, 1980), with a minimum total score of 0 (no restraint) and a maximum of 35 (high restraint).

c Scored on the craving subscale of the Attitudes to Chocolate Questionnaire (Benton et al., 1998), with a minimum total score of 0 (no trait chocolate craving) and a maximum of 100 (high trait chocolate craving).

\section{Restraint}

The participant's intention to restrain her food intake, her concern about body weight and weight fluctuations were measured with the Restraint Scale (Herman \& Polivy, 1980), with a minimum total score of 0 and a maximum of 35. A higher score reflects a higher level of restraint. The scale is sufficiently valid and reliable (Scagliusi et al., 2005; Van Strien, Herman, Engels, Larsen, \& Van Leeuwe, 2007; Williamson et al., 2007).

\section{Bogus chocolate taste test}

The bogus taste test was adapted from Herman and Mack (1975) and is an accepted measure of food intake that is frequently used in eating research. In a bogus chocolate taste test, participants were asked to taste four kinds of chocolate buds (white, milk, dark, extra dark; Barry Callebaut Belgium N.V., Wieze, Belgium). Chocolate types differed in calorific value (in kcal per $100 \mathrm{~g}$ : white, 569; milk, 560; dark, 535; extra dark, 514). The separate bowls in which they were presented were weighed prior to the test and contained approximately $250 \mathrm{~g}$ of chocolate each. Participants were instructed that they could taste as many chocolate buds as needed to complete the taste ratings, and that they were free to consume chocolate buds after they had finished. The chocolate's smell, taste, intensity, appearance, taste persistence and sweetness were rated with six VAS items (0 to 100). The overall intake of chocolate was measured by adding up the consumed weights of the four different chocolate types.

\section{Experimental design}

The experimental design was a mixed design with an exposure group (exposure to the smell of chocolate) versus a control group (exposure to the smell of a control stimulus), with repeated measures of both self-reported chocolate craving and the brain response to chocolate pictures versus neutral control pictures (i.e., visual chocolate stimuli). Chocolate intake was measured after the session. For the current study, only brain responses in the last run (run 7) were analysed because they were closest in time to subsequent intake.

\section{Stimuli}

56 pictures of (products containing) chocolate and 56 neutral pictures of office supplies and utensils not related to food were used as stimuli. Only chocolate pictures without festive associations (such as Valentine, Easter and birthday) were used. Pictures were predominantly purchased online (www.istockphoto.com). Stimuli covered a visual angle of approximately $12^{\circ}$ and were presented in the centre of the screen as pop-out figures on a light grey background. Each picture was presented four times in the course of the scanning session.

\section{Stimulation protocol (visual chocolate and neutral stimuli)}

A blocked design with a block duration of $14.8 \mathrm{~s}^{1}$ was used to present the stimuli (E-Prime version 2.0.8.90 (PST, 1996)). All blocks consisted of eight pictures with a duration of $1850 \mathrm{~ms}$ each, which were chosen randomly without replacement. Half of the stimulus blocks were followed by a question block of $3 \mathrm{~s}$ duration with a yes/ no question about the depicted picture having been presented in the preceding stimulus block. This was done to maintain the attention of the participant, who responded with a button press. A black fixation cross on a light grey background preceded all blocks, with a duration of either $12 \mathrm{~s}$ (before stimulus blocks) or $6 \mathrm{~s}$ (before question blocks). After the last block an additional fixation cross was shown for $12 \mathrm{~s}$.

One run consisted of four chocolate blocks, four neutral blocks, and four question blocks. The order of stimulus blocks was randomised for each of the seven runs, with the constraint that a maximum of two stimulus blocks of the same category would occur subsequently. Question blocks were then inserted randomly, with the constraint that twice they followed a chocolate block and twice a neutral block. This resulted in seven fixed run orders that lasted on average for $270 \mathrm{~s}^{2}$. For each participant, the sequence of these seven runs was randomised.

\section{Session protocol}

The session of 65 min duration started with the first functional run, after which the first exposure to smell (chocolate versus pencil) took place (for a session diagram, please see Frankort et al., 2013). Functional runs and exposures to smell were alternated during the scanning session. For exposure, the participant remained in the scanner and was handed a piece of chocolate (in the exposure group)

\footnotetext{
1 Some blocks in the first two runs were presented up to $15.1 \mathrm{~s}$, probably due to the time it took E-Prime to retrieve the pictures from the local hard disk for the first time and write them to the cache. To synchronise with image acquisition, blocks always started with the reception of a trigger pulse by the scanner indicating the MRI scanner's radiofrequency pulse.

2 The average run duration was longer than the anticipated $264 \mathrm{~s}$ because some of the trigger pulses of the scanner were missed, leading to a prolongation of fixation times between blocks, as waiting times for trigger pulses between blocks were filled with fixation.
} 
or a pencil (in the control group), with the instruction to hold it under her nose and smell it. The piece of chocolate (approximately $4 \mathrm{~cm} \times 2 \mathrm{~cm} \times 1 \mathrm{~cm}$ ) was partly wrapped in an odourless tissue to prevent it from melting. Participants in the chocolate exposure group were instructed to try to crave the chocolate as much as possible, by imagining eating it and feeling it melting in their mouth. The objects were taken back at the end of each exposure. Therefore, there was no exposure to real chocolate or to the pencil during functional runs. Habituation to the smell of the cue was counteracted by instructing the participant to ask for a different one of in total eight brands of milk and dark chocolate (in the exposure group) or a different one of eight pencils (in the control group). In practice, this led to a replacement of the cue at least every few minutes. Every functional run started and ended with a VAS item about the participant's chocolate craving, which could be scored using a joystick on her abdomen. Chocolate craving was additionally assessed every five minutes in the final prolonged exposure cycle, which lasted $20 \mathrm{~min}$. The other exposures were rather short and amounted to 1 , 1, 2, 3 and 3 min respectively. The anatomical measurement was done after the last functional run.

\section{Procedure}

The scanning sessions took place in the afternoon and consisted of seven functional runs and one anatomical measurement. On the scanning day, participants were asked to refrain from eating chocolate products and from drinking coffee or tea (Koppelstaetter et al., 2010). They had to consume a regular lunch 1 to 1.5 hours before the start of the scanning session. Upon arrival, the participant's hunger, restraint, trait craving for chocolate, weight and height were measured. After the participant gave informed consent the scanning session started. After the scanning session, the participant did the bogus chocolate taste test and filled in an exit form in an adjacent room. Then she was thanked and compensated for participation. Debriefing was done by e-mail at the end of the study.

\section{fMRI data acquisition}

A 3T Siemens Magnetom Allegra head-only scanner was used for image acquisition.

Functional T2*-weighted images ( 50 slices, $\mathrm{TR}=3000 \mathrm{~ms}$ ) were acquired using gradient-echo planar imaging parameters, optimised for reducing susceptibility and distortion artefacts in the OFC (Deichmann, Gottfried, Hutton, \& Turner, 2003; Weiskopf, Hutton, Josephs, Turner, \& Deichmann, 2007): TE = 25 ms, oblique axial slices acquired in interleaved order with a negative (i.e. backward) tilt angle of $30^{\circ}$, voxel size $=2 \mathrm{~mm} \times 2 \mathrm{~mm} \times 2.5 \mathrm{~mm}$, field of view $($ FoV $)=256 \mathrm{~mm} \times 192 \mathrm{~mm}$, imaging bandwidth $=2790 \mathrm{~Hz} /$ pixel, echo spacing $=0.42 \mathrm{~ms}$, flip angle $=90^{\circ}$. Each run contained 88 volumes. An optimised anatomical T1-weighted magnetisation-prepared rapid gradient-echo sequence (Deichmann, Good, Josephs, Ashburner, \& Turner, 2000; Mugler \& Brookeman, 1990) was used after the last run, with the following settings: $T R=2250 \mathrm{~ms}$, TE $=2.6 \mathrm{~ms}$, flip angle $=9^{\circ}$, voxel size $=1 \mathrm{~mm} \times 1 \mathrm{~mm} \times 1 \mathrm{~mm}$, echo spacing $=6.9 \mathrm{~ms}$.

\section{Data pre-processing}

Pre-processing and first-level analyses were conducted with BrainVoyager QX version 2.4.1.2052 (BrainInnovation, 2001). The first two volumes of each functional run were excluded due to T1 saturation effects. Pre-processing involved slice scan time correction with cubic spline interpolation, low-frequency noise removal with high-pass temporal filtering $(0.0075 \mathrm{~Hz}$ cut-off), and threedimensional motion correction, using trilinear interpolation for alignment and sinc interpolation for final resampling. Pre-processed data were then aligned to the anatomical scan, resulting in co-registered three-dimensional space data with a voxel resolution of $2 \mathrm{~mm} \times 2 \mathrm{~mm} \times 2 \mathrm{~mm}$ over the course of time for each run. These data were subsequently spatially normalised using Talairach transformation procedures (Talairach \& Tournoux, 1988) and spatially smoothed with a $6 \mathrm{~mm}$ full-width-at-half-maximum isotropic Gaussian Kernel. For group-level analyses, anatomical Talairachstandardised participant data sets were averaged. On this basis a whole-brain mask was generated.

\section{Data analysis}

Regarding chocolate characteristics and overall chocolate intake, group differences were analysed with $t$-tests. In addition, Pearson correlations were calculated between chocolate intake and self-reported chocolate craving, restraint scale scores, trait chocolate craving scores, hunger and time passed between lunch and the start of the scanning session. For brain responses boxcar predictors were set for chocolate, neutral, and question blocks of the last run (run 7). Question block predictors were considered as confounds. A standard haemodynamic response function (Friston et al., 1998) was used to convolve all predictors. The design matrix of the general linear model was generated after adding $z$-transformed motion correction parameters. This modelling approach considers the response to fixation times between blocks as a baseline.

In three separate whole-brain regression analyses, brain responses in the last run (run 7) to chocolate pictures minus neutral pictures were correlated with the total chocolate intake for the whole sample (first analysis) as well as separately for the exposure group (second analysis) and the control group (third analysis). Only voxels with a $p$ value below 0.05 were considered significant, corrected for multiple comparisons at the cluster level by using a Monte Carlo simulation based approach, with 1000 iterations and a voxel size of $2 \mathrm{~mm} \times 2 \mathrm{~mm} \times 2 \mathrm{~mm}$ (Forman et al., 1995; Goebel, Esposito, \& Formisano, 2006). In total 191,443 voxels were contained in the Talairach-standardised whole-brain mask. As a result of these calculations, the minimal cluster size of regions of interest (ROIs) was set to $328 \mathrm{~mm}^{3}$ or 41 functional voxels (first analysis, whole sample), $336 \mathrm{~mm}^{3}$ or 42 functional voxels (second analysis, exposure group only), and $352 \mathrm{~mm}^{3}$ or 44 functional voxels (third analysis, control group only). The Talairach Client (www.talairach.org) (Lancaster et al., 2000) was used to indicate the anatomical localisation of the ROIs. To obtain activation characteristics of these ROIs, average $\beta$ values were extracted for each ROI, run, picture category and participant and were entered into SPSS version 19 for visualisation purposes.

\section{Regression model}

To test the added value of neural activation in run 7 to selfreported chocolate craving for the prediction of chocolate intake, three hierarchical regression models were tested: one for the whole sample, one for the exposure group, and one for the control group. In each model, in step 1, self-reported craving was entered in the model, and in step 2, neural activation that correlated with chocolate intake was added. The self-reported chocolate craving was the average of the craving ratings obtained at the beginning and end of run 7. The neural activation was centred before it was entered into the model. Centering was done across participants, so that each statistical predictor would have a mean of zero. Neural activation was based on the response to chocolate pictures versus neutral pictures that correlated with chocolate intake, in clusters larger than the threshold in each regression analysis (whole sample, exposure group and control group). 
Table 2

Correlations of overall chocolate intake with participant characteristics and measurements of state craving.

\begin{tabular}{|c|c|c|c|c|}
\hline & & $\begin{array}{l}\text { Whole sample } \\
(\mathrm{n}=34)\end{array}$ & $\begin{array}{l}\text { Exposure group } \\
(n=17)\end{array}$ & $\begin{array}{l}\text { Control group } \\
(n=17)\end{array}$ \\
\hline Hunger $^{\mathrm{a}}$ & & -.17 & -.10 & -.20 \\
\hline Time between lunch and scan session & & .10 & -.02 & .22 \\
\hline Restraint $^{\mathrm{b}}$ & & .24 & .23 & .25 \\
\hline Trait chocolate craving $\mathrm{c}$ & & .17 & .18 & .21 \\
\hline \multicolumn{5}{|l|}{ Self-reported chocolate state craving ${ }^{\mathrm{d}}$} \\
\hline \multirow[t]{2}{*}{ Run 1} & Before & .05 & .01 & .05 \\
\hline & After & .11 & .24 & .04 \\
\hline \multirow[t]{2}{*}{ Run 2} & Before & .09 & .26 & .01 \\
\hline & After & .14 & .25 & .09 \\
\hline \multirow[t]{2}{*}{ Run 3} & Before & .10 & .36 & .01 \\
\hline & After & .19 & .32 & .14 \\
\hline \multirow[t]{2}{*}{ Run 4} & Before & .16 & $.53^{*}$ & -.03 \\
\hline & After & .08 & .35 & -.05 \\
\hline \multirow[t]{2}{*}{ Run 5} & Before & .07 & .46 & -.10 \\
\hline & After & .07 & .36 & -.08 \\
\hline \multirow[t]{2}{*}{ Run 6} & Before & .07 & $.52^{*}$ & -.15 \\
\hline & After & .08 & .46 & -.08 \\
\hline \multirow[t]{3}{*}{ During prolonged exposure (20 min) } & At $5 \mathrm{~min}$ & .12 & $.61^{* *}$ & -.14 \\
\hline & At $10 \mathrm{~min}$ & .06 & $.53^{*}$ & -.16 \\
\hline & At $15 \mathrm{~min}$ & .10 & $.57^{*}$ & -.12 \\
\hline \multirow[t]{2}{*}{ Run 7} & Before & .06 & $.50^{*}$ & -.20 \\
\hline & After & .09 & .42 & -.10 \\
\hline
\end{tabular}

Note: Significance indications: ${ }^{*} p<.05 ;{ }^{* *} p<.01$ (uncorrected).

a-c See notes of Table 1.

d Scored on $100 \mathrm{~mm}$ VAS, ranging from 0 (not craving chocolate at all) to 100 (craving chocolate very much).

\section{Results}

Chocolate intake and self-reported craving

Overall chocolate intake did not differ between groups (see Table 1), although it had been expected that chocolate CERP would lead to reduced intake as compared to the neutral control exposure. Chocolate intake was not correlated with restraint scale scores, trait chocolate craving scores, hunger, or time passed since lunch was eaten, in either the exposure or the control group, or the whole sample (see Table 2). No significant correlations were found between self-reported chocolate craving and subsequent intake in the whole sample or just the control group. However, within the exposure group, chocolate craving showed significant correlations with overall chocolate intake (Table 2).

\section{Chocolate characteristics}

Chocolate characteristic ratings, as measured in the bogus taste test, did not differ between groups, except for the smell of milk chocolate (Table 3).

\section{Neural predictors of chocolate intake}

The whole-brain regression analysis (for the whole sample) yielded one ROI larger than the minimal cluster size, in which the activation (response to chocolate pictures versus neutral pictures) of all individual voxels was positively correlated with intake. This ROI was located in the right anterior PFC (cluster A in Fig. 1 and Table 4). The second analysis, performed with only the exposure group, resulted in two ROIs (clusters B and C in Fig. 1 and Table 4) with a positive correlation of activation and subsequent chocolate intake. These were located in the right caudate and the left lateral frontopolar cortex. The third regression analysis with only the control group produced two ROIs (clusters D and E in Fig. 1 and Table 4) with a negative correlation between activation and intake, in the left dorsolateral and the left mid-dorsolateral PFC surrounding the inferior frontal sulcus. Independent samples $t$ tests showed that within each cluster, groups did not differ on average activation, all $t \mathrm{~s}<.67$, all $p s>.51$.
Table 3

Chocolate characteristics.

\begin{tabular}{|c|c|c|c|c|c|c|}
\hline & \multicolumn{2}{|c|}{$\begin{array}{l}\text { Exposure group } \\
(n=17)\end{array}$} & \multicolumn{2}{|c|}{$\begin{array}{l}\text { Control group } \\
(n=17)\end{array}$} & \multirow[b]{2}{*}{$t(32)$} & \multirow[b]{2}{*}{$p$} \\
\hline & M & SD & M & SD & & \\
\hline \multicolumn{7}{|l|}{ Extra dark chocolate } \\
\hline Visual attractiveness & 29.4 & 22.0 & 31.5 & 20.2 & .30 & .77 \\
\hline Smell & 50.1 & 27.1 & 59.2 & 28.3 & .95 & .34 \\
\hline Taste & 52.1 & 25.7 & 46.2 & 32.2 & .58 & .56 \\
\hline Sweetness & 19.8 & 11.6 & 25.4 & 18.3 & 1.06 & .30 \\
\hline Intensity & 75.5 & 11.5 & 80.5 & 19.4 & $.91^{\mathrm{a}}$ & $.37^{\mathrm{a}}$ \\
\hline Taste persistence & 77.8 & 18.1 & 75.4 & 17.5 & .40 & .70 \\
\hline \multicolumn{7}{|l|}{ Dark chocolate } \\
\hline Visual attractiveness & 33.2 & 21.3 & 33.8 & 22.1 & .09 & .93 \\
\hline Smell & 57.3 & 24.7 & 59.0 & 25.2 & .20 & .84 \\
\hline Taste & 56.9 & 25.5 & 53.1 & 27.5 & .42 & .68 \\
\hline Sweetness & 32.5 & 19.6 & 38.2 & 13.9 & .98 & .34 \\
\hline Intensity & 70.4 & 16.0 & 72.9 & 16.1 & .46 & .65 \\
\hline Taste persistence & 69.2 & 18.0 & 75.6 & 12.5 & 1.21 & .24 \\
\hline \multicolumn{7}{|l|}{ Milk chocolate } \\
\hline Visual attractiveness & 76.4 & 13.6 & 81.2 & 20.2 & .82 & .42 \\
\hline Smell & 64.2 & 19.4 & 78.4 & 12.7 & $2.53^{\mathrm{b}}$ & $.02^{*, \mathrm{~b}}$ \\
\hline Taste & 80.1 & 16.2 & 77.2 & 24.1 & .40 & .69 \\
\hline Sweetness & 68.0 & 17.8 & 73.6 & 10.1 & 1.13 & .27 \\
\hline Intensity & 56.9 & 21.4 & 59.9 & 22.2 & .41 & .69 \\
\hline Taste persistence & 54.5 & 20.0 & 65.0 & 17.8 & 1.61 & .12 \\
\hline \multicolumn{7}{|l|}{ White chocolate } \\
\hline Visual attractiveness & 82.2 & 7.9 & 83.1 & 12.1 & .25 & .80 \\
\hline Smell & 60.5 & 22.7 & 67.2 & 24.4 & .83 & .41 \\
\hline Taste & 84.6 & 12.4 & 79.7 & 12.5 & 1.14 & .26 \\
\hline Sweetness & 80.5 & 15.3 & 80.8 & 10.8 & .07 & .95 \\
\hline Intensity & 64.1 & 17.7 & 53.9 & 23.0 & 1.45 & .16 \\
\hline Taste persistence & 62.4 & 10.7 & 56.2 & 14.4 & 1.42 & .17 \\
\hline
\end{tabular}

Note: Significance indications: ${ }^{*} p<.05$ (uncorrected).

a Variances of this rating could not be considered equal between groups, degrees of freedom $=25.99$.

b Variances of this rating could not be considered equal between groups, degrees of freedom $=27.54$. 


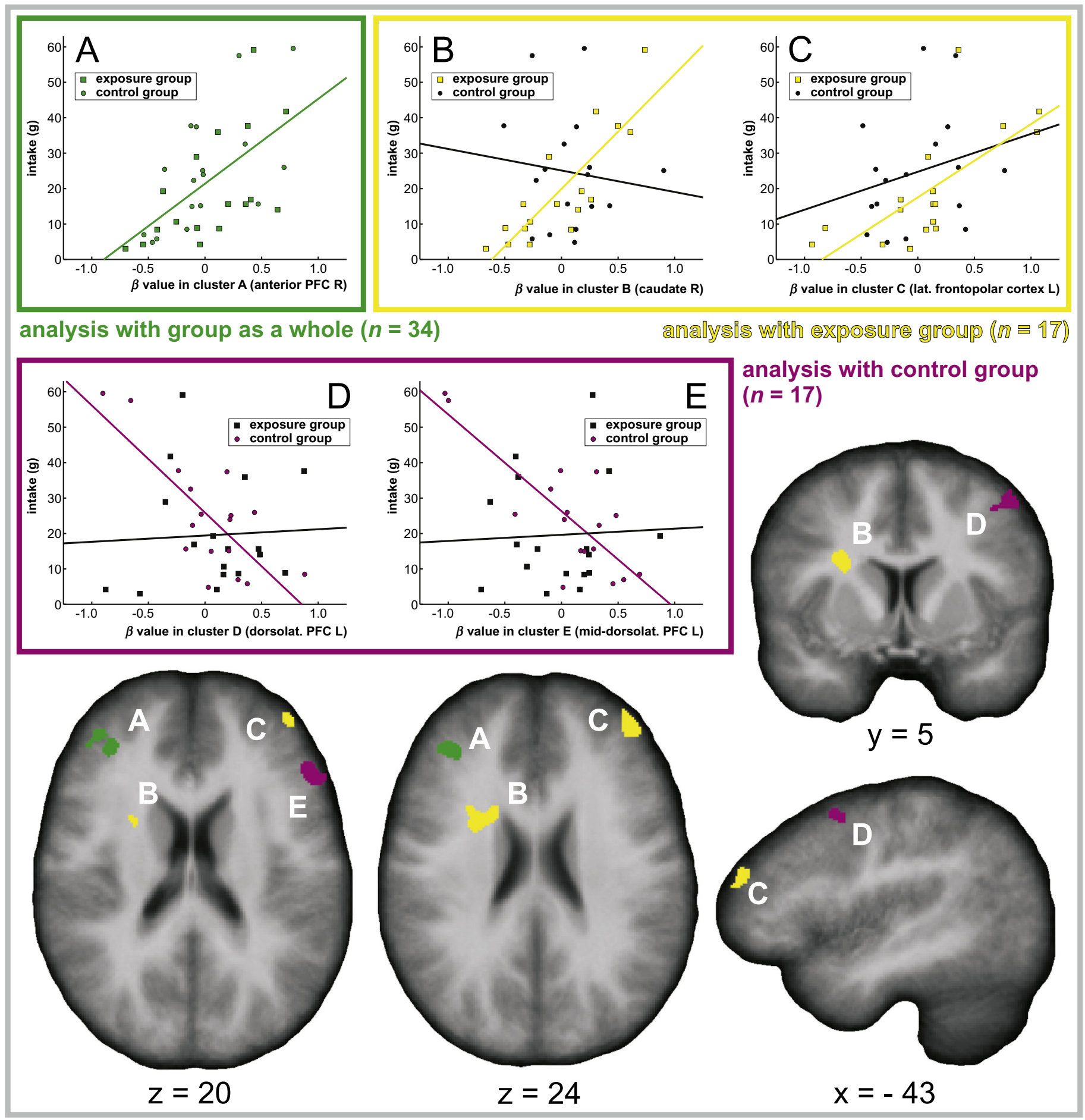

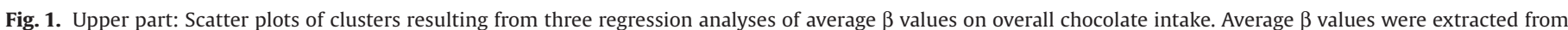

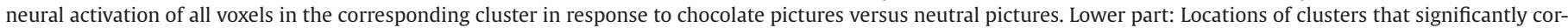

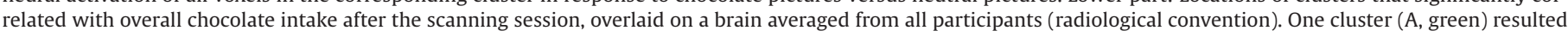

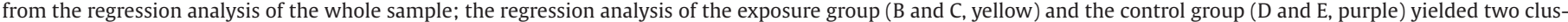

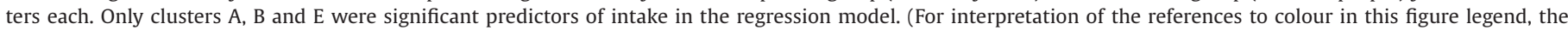
reader is referred to the web version of this article).

Regression model with self-reported craving and neural correlates of intake

Step 1 of the regression models showed that the regression of selfreported craving on intake was not significant, neither in the whole sample nor in the separate groups (Table 5). After adding neural activation to the model in step 2, all three regression analyses (one with the whole sample, one with only the exposure group and one with only the control group) were significant. Variance explained by neural activation was above and beyond the variance explained by self-reported craving alone in all three regression analyses. Significant contributions to explained variance were made by the right anterior PFC (cluster 
Table 4

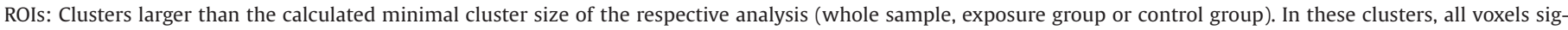
nificantly correlated with overall chocolate intake in terms of their activation in response to chocolate pictures minus neutral pictures.

\begin{tabular}{|c|c|c|c|c|c|c|c|c|c|c|}
\hline \multirow[t]{2}{*}{ ROI } & \multirow[t]{2}{*}{ Anatomical label } & \multirow[t]{2}{*}{$p^{\mathrm{a}}$} & \multirow[t]{2}{*}{ Sign of correlation } & \multirow[t]{2}{*}{ Estimated $\mathrm{BA}^{\mathrm{b}}$} & \multirow[t]{2}{*}{ Size $\left(\mathrm{mm}^{3}\right)$} & \multicolumn{5}{|c|}{ Peak voxel values ${ }^{c}$} \\
\hline & & & & & & $\mathrm{x}$ & $\mathrm{y}$ & $\mathrm{z}$ & $r_{\text {intake-beta }}{ }^{\mathrm{d}}$ & $r_{\text {craving-beta }}{ }^{\mathrm{e}}$ \\
\hline \multicolumn{11}{|c|}{ Whole sample $(n=34)$} \\
\hline A & Anterior PFC (MFG) R & .0002 & + & 10,9 & 412 & 35 & 38 & 23 & $.57^{* *}$ & .24 \\
\hline \multicolumn{11}{|c|}{ Exposure group $(n=17)$} \\
\hline B & Caudate body, claustrum R & .00003 & + & & 501 & 19 & 11 & 23 & $.76^{* *}$ & .39 \\
\hline $\mathrm{C}$ & Lateral frontopolar cortex (MFG/SFG) L & .002 & + & $10,9,46$ & 412 & -40 & 53 & 23 & $.75^{* *}$ & .38 \\
\hline \multicolumn{11}{|c|}{ Control group $(n=17)$} \\
\hline D & Dorsolateral PFC (MFG) L & .0004 & - & 6 & 379 & -46 & 7 & 51 & $-.88^{* *}$ & .09 \\
\hline $\mathrm{E}$ & Mid-dorsolateral PFC surrounding the IFS (MFG/IFG) L & .00009 & - & 46,45 & 433 & -55 & 25 & 19 & $-.78^{* *}$ & .02 \\
\hline
\end{tabular}

Note: Significance indications: ${ }^{*} p<.05 ;{ }^{* *} p<.01 ;{ }^{* * *} p<.001$ (uncorrected).

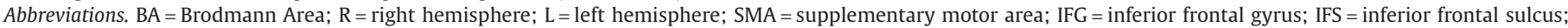
$\mathrm{MFG}=$ middle frontal gyrus; $\mathrm{SFG}=$ superior frontal gyrus.

a This is the significance indication of averaged beta values of the cluster as a single predictor of intake.

b Identified with the "nearest grey matter" option in the Talairach Client (www.talairach.org) (Lancaster et al., 2000).

c Voxel coordinates are reported in Talairach space.

d This is the correlation between intake and the beta value of the peak voxel in response to chocolate pictures versus neutral pictures in run 7 . This correlation coefficient should be interpreted with caution, because these clusters were extracted based on high correlation (double dipping).

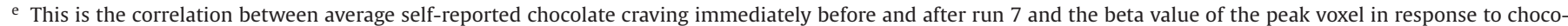
late pictures versus neutral pictures in run 7.

A in the analysis with the whole sample), the right caudate (cluster B in the exposure group analysis) and, with a negative sign, the left middorsolateral PFC (cluster E in the control group analysis).

\section{Discussion}

Building on a previous study (Frankort et al., 2013), the current study investigated the self-reported and neural predictors of chocolate intake after having been exposed during approximately one hour to chocolate (exposure group) or to a control stimulus (control group). In three regression models it was tested if there are neural correlates in brain

Table 5

Hierarchical multiple regression analysis predicting chocolate intake from selfreported craving and neural correlates. Variances explained $\left(\Delta R^{2}\right)$ by neural correlates are listed for comparative purposes only.

\begin{tabular}{|c|c|c|c|}
\hline Predictor & $\Delta R^{2}$ & $\beta$ & $\begin{array}{l}\text { Significant } \\
\text { contribution } \\
\text { of neural } \\
\text { correlates? }\end{array}$ \\
\hline \multicolumn{4}{|l|}{ Whole sample $(n=34)$} \\
\hline Step 1: self-reported craving only & .006 & & \\
\hline $\begin{array}{l}\text { Average of craving ratings before and after } \\
\text { run } 7\end{array}$ & & .08 & \\
\hline Step 2: self-reported plus neural correlates & $.36^{* * *}$ & & Yes \\
\hline $\begin{array}{l}\text { Average of craving ratings before and after } \\
\text { run } 7\end{array}$ & & -.06 & \\
\hline Activation in cluster $\mathrm{A}$ in run 7 & & $.60^{* * * *}$ & \\
\hline \multicolumn{4}{|l|}{ Exposure group $(n=17)$} \\
\hline Step 1: self-reported craving only & .22 & & \\
\hline $\begin{array}{l}\text { Average of craving ratings before and after } \\
\text { run } 7\end{array}$ & & .47 & \\
\hline Step 2: self-reported plus neural correlates & $.77^{* * * *}$ & & Yes \\
\hline $\begin{array}{l}\text { Average of craving ratings before and after } \\
\text { run } 7\end{array}$ & & .22 & \\
\hline Activation in cluster B in run 7 & & $.57^{*}$ & \\
\hline Activation in cluster $C$ in run 7 & & .27 & \\
\hline \multicolumn{4}{|l|}{ Control group $(n=17)$} \\
\hline Step 1: self-reported craving only & .02 & & \\
\hline $\begin{array}{l}\text { Average of craving ratings before and after } \\
\text { run } 7\end{array}$ & & -.16 & \\
\hline Step 2: self-reported plus neural correlates & $.72^{* * *}$ & & Yes \\
\hline $\begin{array}{l}\text { Average of craving ratings before and after } \\
\text { run } 7\end{array}$ & & -.22 & \\
\hline Activation in cluster D in run 7 & & -.21 & \\
\hline Activation in cluster $\mathrm{E}$ in run 7 & & $-.66^{*}$ & \\
\hline
\end{tabular}

Note: Significance indications: ${ }^{*} p<.05 ;{ }^{* *} p<.01 ;{ }^{* * *} p<.001$ (uncorrected). regions associated with reward that predict intake, and if the variance explained by these neural correlates is above and beyond the variance explained by self-reported craving. For the whole sample, selfreported chocolate craving did not correlate at any point in time with subsequent intake, which was unexpected. Interestingly, activation in the right anterior PFC was positively correlated with intake and significantly contributed to the explained variance of intake. There was no group difference in average activation levels in this region. Although the function of this region is not very specific as it is active during multiple and diverse cognitive tasks (Ramnani \& Owen, 2004), a systematic review of brain lesions in eating disorders (Uher \& Treasure, 2005) found a consistent association of right frontal lobe lesions with weight loss. The same region's taste response to appetising food versus water (at MNI coordinates 45, 45, 9) was found to correlate positively with BMI (Stice et al., 2010). Moreover, the activation of this part of the PFC (at TAL coordinates $24,47,11$ ) elicited by alcohol-associated cues compared with affectively neutral and abstract pictures has been associated with the intake of alcohol in abstinent alcoholics who subsequently relapsed compared with control subjects (Grüsser et al., 2004). Therefore, the predictive validity of this region's activation on intake is in line with existing literature.

The control group showed no correlation between self-reported craving during the session and chocolate intake after the session. On a neural level, two brain regions in the left dorsolateral and middorsolateral PFC correlated with intake, with the latter contributing significantly to explained variance of intake. Correlation with chocolate intake was negative in both regions, which is not surprising, given the fact that both have been associated with cognitive control, self-control and inhibition (Coutlee \& Huettel, 2012; Figner et al., 2010; Petrides, 2005). More specifically, an increase in regional cerebral blood flow in the vicinity of these regions (at Talairach coordinates $-28,17,50$ and $-48,30,3$ ) was associated with a decrease in reward value (Small, Zatorre, Dagher, Evans, \& Jones-Gotman, 2001) and in a prospective study, activation in both regions (at MNI coordinates 44, 10, 52 and $-48,26,14$ ) in response to food versus control stimuli was predictive of subsequent weight loss after 12 weeks (Murdaugh et al., 2012). Moreover, a voxel-based morphometry study showed that a reduction of grey matter in almost exactly the same region (at MNI coordinates -48 , 9,51 ) in the left dorsolateral PFC was predictive of an increase in BMI after one year (Yokum et al., 2012). The negative correlations in our study with the control group intake confirm that these regions are implicated in the inhibition of food reward. Slightly surprising 
was the fact that only inhibitory brain regions predicted intake in the control group (instead of brain reward regions). It appeared that, at the end of the session, inhibitory activation in response to chocolate versus neutral pictures did predict subsequent intake whereas activation in reward regions did not, although the average activation in the inhibitory ROIs did not differ from the average activation in these regions in the exposure group. Considering that our participants scored low on a measure of dietary restraint, it may be expected that these results would be more pronounced in a sample of participants scoring high on dietary restraint. However, this remains for future research.

In the exposure group, self-reported craving was related to chocolate intake at certain moments during the session. However, the average of the craving ratings immediately before and after run 7 did not significantly contribute to the explained variance in the regression analysis. Regarding the BOLD response, intake did correlate with neural activation in the right caudate and the left lateral frontopolar cortex, with a significant contribution of the caudate activation to explained variance of intake, above and beyond the variance explained by self-reported craving. The more active these regions were, the more the chocolate-exposed participants ate after the session. Although the frontopolar cortex has been found to exercise control over highly abstract plans, goals, and response strategies (Coutlee \& Huettel, 2012), regions in the left lateral frontopolar cortex close to that identified here have also been implicated in reward and craving, like monetary reward (at TAL coordinates $-33,51,27$ ) (Pochon et al., 2002) and craving for cocaine (at MNI coordinates $-36,42,28$ ) (Gorelick et al., 2005), but it is also active during many complex cognitive tasks (Ramnani \& Owen, 2004). Activation of the other cluster in this exposure group analysis, the caudate, has been correlated with the reward value of chocolate (Small et al., 2001), although this was a more anterioventral part of the caudate (at TAL coordinates 15, 20,9) and with meal pleasantness in general (at TAL coordinates 12, 10, 20) (Small, Jones-Gotman, \& Dagher, 2003). In obese participants, the caudate nucleus has been found to be more activated than in healthy-weight controls in response to pictures of food versus neutral pictures, even though other parts of the caudate were active than the one we found (Rothemund et al., 2007; Stoeckel et al., 2008). The increased caudate activation predicting increased chocolate intake after chocolate exposure fits with these findings.

It must be noted that intake was predicted by different brain regions in the exposure group as compared to the control group, even though no group differences in absolute level of activation were found between the groups in any of these regions. Only activation in reward regions correlated with intake in the exposure group, and only activation in inhibitory regions correlated with intake in the control group. We speculate that the exposure group experienced a greater focus on palatability, and, as a consequence, activation in reward regions was mostly predictive of intake. So, the consumption of these participants may have been driven mostly by palatability considerations. It may also explain why only in the exposure group a correlation between self-reported craving during the session and intake was found. That is, a greater correspondence between selfreported craving and intake was found because both measures may have been mostly driven by palatability considerations. In the control group, health considerations may have been more relevant, presumably resulting in a negative correlation between activation in inhibitory brain regions and intake, and in a lack of correlation between self-reported craving and intake. One should keep in mind that the measurement of chocolate craving was measured with a single VAS question. If a more comprehensive chocolate craving measure would have been used, correlations between craving and intake might have been larger. Regarding the ratings of chocolate characteristics, the groups did not differ except for the rating of the smell of milk chocolate. The exposure group rated this smell as less pleasant than the control group. This may be the result of the exposure with real chocolate in the exposure group. However, no group differences were found regarding the smell of the other chocolate types, so the effect can be considered small.

As these results show, the CERP manipulation did influence the predictive validity of the neural correlates of chocolate craving on intake. However, the CERP manipulation was not as effective as it was expected to be, because overall chocolate intake was similar in both groups, although it was expected to be smaller in the exposure group as compared to the control group. One explanation for the lack of an effect of exposure on chocolate consumption could be the specific demands of the bogus taste test. Maybe the exposure only affected the decision to eat or not, but not so much the amount eaten, which is the dependent variable in the bogus taste test. Alternatively, the lack of an effect on intake may be due to the fact that extinction of craving was not attained in the chocolate exposure group, which may have been the result of the olfactory exposure being interrupted too often by scans (see Frankort et al., 2013). In addition, extinction may not have been attained because the bond between the conditioned stimulus (CS) and the unconditioned stimulus (US) is likely particularly strong for chocolate, as this food is generally very much liked and people typically have had many exposures to chocolate, resulting in many opportunities for the CS-US bond to strengthen. So, it is likely that one session is not enough to attain extinction. Another possibility is that the exposure procedure did break the link between the olfactory cues and consumption, but not between the visual cues and consumption.

In summary, all three regression analyses suggest that neural correlates predict subsequent behaviour (i.e., chocolate intake) above and beyond self-reported chocolate craving, which confirmed our hypothesis. Self-reported craving did not significantly contribute to the prediction of subsequent intake. In contrast, the BOLD response to chocolate pictures versus neutral pictures in the caudate, which has been associated with long-term weight gain in previous studies, was a significant predictor of intake for the chocolate exposure group. Also the activation in the mid-dorsolateral PFC negatively predicted subsequent chocolate intake in the control group. This region has been linked to weight loss in previous studies. Further, the response in the right anterior PFC significantly predicted intake in the whole sample. Lesions in this region have been associated with weight loss. Therefore, even though we did not measure weight change, our findings might provide a missing link between brain activation and long-term weight change by showing an association between brain activation and subsequent intake. Furthermore, only reward regions correlated with intake in the exposure group, and only inhibitory regions correlated with intake in the control group. In other words, the prevailing influence on subsequent intake in the exposure group was reward. In the control group, this prevailing influence was inhibition. In conclusion, neural correlates were more predictive of subsequent intake than was self-reported craving, for the chocolate exposure group, the control group and the whole sample. However, the brain regions found to be predictive differed between groups, both in location and in assumed functionality (reward in the exposure group versus inhibition in the control group). This can be considered as an effect of the CERP manipulation, which is noteworthy because of the fact that brain correlates were a better predictor of subsequent intake than self-reported craving. It remains to be investigated if the same results would be achieved after addition of other self-reported measures to the craving measure, like eating behaviour risk factors and emotion regulation abilities. Also it would be interesting to explore if, after an effective CERP, reward region activation would still be predictive of subsequent intake and if activation in reward regions would extinguish together with craving. 


\section{References}

Batterink, L., Yokum, S., \& Stice, E. (2010). Body mass correlates inversely with inhibitory control in response to food among adolescent girls. An fMRI study. Neuroimage, 52, 1696-1703.

Benton, D., Greenfield, K., \& Morgan, M. (1998). The development of the attitudes to chocolate questionnaire. Personality and Individual Differences, 24, 513-520.

Berridge, K. C., Ho, C.-Y., Richard, J. M., \& DiFeliceantonio, A. G. (2010). The tempted brain eats. Pleasure and desire circuits in obesity and eating disorders. Brain Research, 1350, 43-64.

Berthoud, H. R., Lenard, N. R., \& Shin, A. C. (2011). Food reward, hyperphagia, and obesity. American Journal of Physiology - Regulatory Integrative and Comparative Physiology, 300, R1266-R1277.

Boutelle, K. N., Zucker, N. L., Peterson, C. B., Rydell, S. A., Cafri, G., \& Harnack, L. (2011). Two novel treatments to reduce overeating in overweight children. A randomized controlled trial. Journal of Consulting and Clinical Psychology, 79, 759-771.

BrainInnovation. (2001). BrainVoyager QX (Version 2.4.1.2052, 32-bit) [Computer software]. <http://www.brainvoyager.com>.

Carnell, S., Gibson, C., Benson, L., Ochner, C. N., \& Geliebter, A. (2012). Neuroimaging and obesity. Current knowledge and future directions. Obesity Reviews, 13, 43-56.

Coutlee, C. G., \& Huettel, S. A. (2012). The functional neuroanatomy of decision making. Prefrontal control of thought and action. Brain Research, 1428, 3-12.

Cramer, K., \& Hartleib, M. (2001). The attitudes to chocolate questionnaire. A psychometric evaluation. Personality and Individual Differences, 31, 931-942.

Deichmann, R., Good, C. D., Josephs, O., Ashburner, J., \& Turner, R. (2000). Optimization of 3-D MP-RAGE sequences for structural brain imaging. Neuroimage, 12, 112-127.

Deichmann, R., Gottfried, J. A., Hutton, C., \& Turner, R. (2003). Optimized EPI for fMRI studies of the orbitofrontal cortex. Neuroimage, 19, 430-441.

Falk, E. B., Berkman, E. T., Mann, T., Harrison, B., \& Lieberman, M. D. (2010). Predicting persuasion-induced behavior change from the brain. Journal of Neuroscience, 30 , 8421-8424.

Falk, E. B., Berkman, E. T., Whalen, D., \& Lieberman, M. D. (2011). Neural activity during health messaging predicts reductions in smoking above and beyond self-report. Health Psychology, 30, 177-185.

Figner, B., Knoch, D., Johnson, E. J., Krosch, A. R., Lisanby, S. H., Fehr, E., et al. (2010). Lateral prefrontal cortex and self-control in intertemporal choice. Nature Neuroscience, 13, 538-539.

Forman, S. D., Cohen, J. D., Fitzgerald, M., Eddy, W. F., Mintun, M. A., \& Noll, D. C. (1995). Improved assessment of significant activation in functional magnetic resonance imaging (fMRI). Use of a cluster-size threshold. Magnetic Resonance in Medicine, 33, 636-647.

Frankort, A., Roefs, A., Siep, N., Roebroeck, A., Havermans, R., \& Jansen, A. (2012). Reward activity in satiated overweight women is decreased during unbiased viewing but increased when imagining taste. An event-related fMRI study. International Journal of Obesity (2005), 36, 627-637.

Frankort, A., Roefs, A., Siep, N., Roebroeck, A., Havermans, R., \& Jansen, A. (2013). The craving stops before you feel it. Neural correlates of chocolate craving during cue exposure with response prevention. Cerebral Cortex (New York, N.Y.: 1991), [Epub ahead of print].

Friston, K. J., Fletcher, P., Josephs, O., Holmes, A., Rugg, M. D., \& Turner, R. (1998). Event-related fMRI. Characterizing differential responses. Neuroimage, 7, 30-40.

Goebel, R., Esposito, F., \& Formisano, E. (2006). Analysis of functional image analysis contest (FIAC) data with brainvoyager QX. From single-subject to cortically aligned group general linear model analysis and self-organizing group independent component analysis. Human Brain Mapping, 27, 392-401.

Gorelick, D. A., Kim, Y. K., Bencherif, B., Boyd, S. J., Nelson, R., Copersino, M., et al. (2005). Imaging brain mu-opioid receptors in abstinent cocaine users. Time course and relation to cocaine craving. Biological Psychiatry, 57, 1573-1582.

Grüsser, S. M., Wrase, J., Klein, S., Hermann, D., Smolka, M. N., Ruf, M., et al. (2004). Cue-induced activation of the striatum and medial prefrontal cortex is associated with subsequent relapse in abstinent alcoholics. Psychopharmacology, 175, 296-302.

Hare, T. A., Malmaud, J., \& Rangel, A. (2011). Focusing attention on the health aspects of foods changes value signals in vmPFC and improves dietary choice. The Journal of Neuroscience : The Official Journal of the Society for Neuroscience, 31, 1107711087

Herman, C. P., \& Mack, D. (1975). Restrained and unrestrained eating. Journal of Personality, 43, 647-660.

Herman, C. P., \& Polivy, J. (1980). Restrained eating. In A. J. Stunkard (Ed.), Obesity (pp. 208-225). Philadelphia: Saunders.

Jansen, A., Broekmate, J., \& Heymans, M. (1992). Cue-exposure vs self-control in the treatment of binge eating. A pilot study. Behaviour Research and Therapy, 30, 235-241.

Jansen, A., Havermans, R., \& Nederkoorn, C. (2011). Cued overeating. In V. R. Preedy, R. R. Watson, \& C. R. Martin (Eds.), Handbook of Behavior, Food and Nutrition (pp. 1431-1443). New York: Springer New York.

Jansen, A., Van den Hout, M. A., De Loof, C., Zandbergen, J., \& Griez, E. (1989). A case of bulimia successfully treated by cue exposure. Journal of Behavior Therapy and Experimental Psychiatry, 20, 327-332.

Kennedy, S. H., Katz, R., Neitzert, C. S., Ralevski, E., \& Mendlowitz, S. (1995). Exposure with response prevention treatment of anorexia nervosa-bulimic subtype and bulimia nervosa. Behaviour Research and Therapy, 33, 685-689.

Kishinevsky, F. I., Cox, J. E., Murdaugh, D. L., Stoeckel, L. E., Cook, E. W., \& Weller, R. E. (2012). fMRI reactivity on a delay discounting task predicts weight gain in obese women. Appetite, 58, 582-592.
Koppelstaetter, F., Poeppel, T. D., Siedentopf, C. M., Ischebeck, A., Kolbitsch, C. Mottaghy, F. M., et al. (2010). Caffeine and cognition in functional magnetic resonance imaging. Journal of Alzheimer's Disease, 20(Suppl. 1), S71-S84.

Kosten, T. R., Scanley, B. E., Tucker, K. A., Oliveto, A., Prince, C., Sinha, R., et al. (2006). Cue-induced brain activity changes and relapse in cocaine-dependent patients. Neuropsychopharmacology, 31, 644-650.

Kringelbach, M. L. (2009). The hedonic brain. A functional neuroanatomy of human pleasure. In M. L. Kringelbach \& K. C. Berridge (Eds.), Pleasures of the Brain (pp. 202-221). New York: Oxford University Press.

Lancaster, J. L., Woldorff, M. G., Parsons, L. M., Liotti, M., Freitas, C. S., Rainey, L., et al (2000). Automated Talairach atlas labels for functional brain mapping. Human Brain Mapping, 10, 120-131.

Lawrence, N. S., Hinton, E. C., Parkinson, J. A., \& Lawrence, A. D. (2012). Nucleus accumbens response to food cues predicts subsequent snack consumption in women and increased body mass index in those with reduced self-control. Neuroimage, 63, 415-422.

Martinez-Mallén, E., Castro-Fornieles, J., Lázaro, L., Moreno, E., Morer, A., Font, E. et al. (2007). Cue exposure in the treatment of resistant adolescent bulimia nervosa. The International Journal of Eating Disorders, 40, 596-601.

Mehta, S., Melhorn, S. J., Smeraglio, A., Tyagi, V., Grabowski, T., Schwartz, M. W., et al (2012). Regional brain response to visual food cues is a marker of satiety that predicts food choice. The American Journal of Clinical Nutrition, 96, 989999.

Mugler, J. P., \& Brookeman, J. R. (1990). Three-dimensional magnetization-prepared rapid gradient-echo imaging (3D MP RAGE). Magnetic Resonance in Medicine, 15, 152-157.

Murdaugh, D. L., Cox, J. E., Cook, E. W., \& Weller, R. E. (2012). fMRI reactivity to high-calorie food pictures predicts short- and long-term outcome in a weight-loss program. Neuroimage, 59, 2709-2721.

Müller, J., Dettmer, D., \& Macht, M. (2008). The attitudes to chocolate questionnaire Psychometric properties and relationship to dimensions of eating. Appetite, 50 , 499-505.

Nisbett, R. E., \& Wilson, T. D. (1977). Telling more than we can know. Verbal reports on mental processes. Psychological Review, 84, 231-259.

Petrides, M. (2005). Lateral prefrontal cortex. Architectonic and functional organization. Philosophical Transactions of the Royal Society of London. Series B, Biological Sciences, 360, 781-795.

Pochon, J. B., Levy, R., Fossati, P., Lehericy, S., Poline, J. B., Pillon, B., et al. (2002). The neural system that bridges reward and cognition in humans. An fMRI study. Proceedings of the National Academy of Sciences of the United States of America, 99, 5669-5674.

PST. (1996). E-Prime (Version 2.0.8.90) [Computer software]. <http://www .pstnet.com>.

Ramnani, N., \& Owen, A. M. (2004). Anterior prefrontal cortex. Insights into function from anatomy and neuroimaging. Nature Reviews. Neuroscience, 5, $184-194$.

Rolls, E. T. (2011). Taste, olfactory and food texture reward processing in the brain and obesity. International Journal of Obesity (2005), 35, 550-561.

Rothemund, Y., Preuschhof, C., Bohner, G., Bauknecht, H.-C., Klingebiel, R., Flor, H. et al. (2007). Differential activation of the dorsal striatum by high-calorie visual food stimuli in obese individuals. Neuroimage, 37, 410-421.

Scagliusi, F. B., Polacow, V. O., Cordás, T. A., Coelho, D., Alvarenga, M., Philippi, S. T., et al. (2005). Test-retest reliability and discriminant validity of the Restraint Scale translated into Portuguese. Eating Behaviors, 6, 85-93.

Schwarz, N., \& Oyserman, D. (2001). Asking questions about behavior. Cognition, communication, and questionnaire construction. The American Journal of Evaluation, 22, 127-160.

Small, D. M. (2009). Individual differences in the neurophysiology of reward and the obesity epidemic. International Journal of Obesity (2005), 33(Suppl. 2), S44-S48.

Small, D. M., Jones-Gotman, M., \& Dagher, A. (2003). Feeding-induced dopamine release in dorsal striatum correlates with meal pleasantness ratings in healthy human volunteers. Neuroimage, 19, 1709-1715.

Small, D. M., Zatorre, R. J., Dagher, A., Evans, A. C., \& Jones-Gotman, M. (2001). Changes in brain activity related to eating chocolate. From pleasure to aversion. Brain: A Journal of Neurology, 124, 1720-1733.

Smeets, P. A. M., Charbonnier, L., Van Meer, F., Van der Laan, L. N., \& Spetter, M. S. (2012). Food-induced brain responses and eating behaviour. The Proceedings of the Nutrition Society, 71, 511-520.

Spetter, M. S., de Graaf, C., Viergever, M. A., \& Smeets, P. A. M. (2012). Anterior cingulate taste activation predicts ad libitum intake of sweet and savory drinks in healthy, normal-weight men. The Journal of Nutrition, 142, 795-802.

Stice, E., Yokum, S., Bohon, C., Marti, N., \& Smolen, A. (2010). Reward circuitry responsivity to food predicts future increases in body mass. Moderating effects of DRD2 and DRD4. Neuroimage, 50,1618-1625.

Stoeckel, L. E., Murdaugh, D. L., Cox, J. E., Cook, E. W., \& Weller, R. E. (2013). Greater impulsivity is associated with decreased brain activation in obese women during a delay discounting task. Brain Imaging and Behavior, 7, 116-128.

Stoeckel, L. E., Weller, R. E., Cook, E. W., Twieg, D. B., Knowlton, R. C., \& Cox, J. E. (2008) Widespread reward-system activation in obese women in response to pictures of high-calorie foods. Neuroimage, 41, 636-647.

Swinburn, B. A., Sacks, G., Lo, S. K., Westerterp, K. R., Rush, E. C., Rosenbaum, M., et al. (2009). Estimating the changes in energy flux that characterize the rise in obesity prevalence. The American Journal of Clinical Nutrition, 89, 1723-1728.

Talairach, J., \& Tournoux, P. (1988). Co-Planar Stereotaxic Atlas of the Human Brain: 3-Dimensional Proportional System. An Approach to Cerebral Imaging. New York: Thieme Medical Publishers. 
Toro, J., Cervera, M., Feliu, M. H., Garriga, N., Jou, M., Martinez, E., et al. (2003). Cue exposure in the treatment of resistant bulimia nervosa. The International Journal of Eating Disorders, 34, 227-234.

Uher, R., \& Treasure, J. (2005). Brain lesions and eating disorders. Journal of Neurology, Neurosurgery, and Psychiatry, 76, 852-857.

Van der Laan, L. N., De Ridder, D. T. D., Viergever, M. A., \& Smeets, P. A. M. (2012) Appearance matters. Neural correlates of food choice and packaging aesthetics. PLOS ONE, 7, e41738.

Van der Laan, L. N., De Ridder, D., Viergever, M., \& Smeets, P. (2011). The first taste is always with the eyes. A meta-analysis on the neural correlates of processing visual food cues. Neuroimage, 55, 296-303.

Van Gucht, D., Vansteenwegen, D., Beckers, T., Hermans, D., Baeyens, F., Van den Bergh, O. (2008). Repeated cue exposure effects on subjective and physiological indices of chocolate craving. Appetite, 50, 19-24.
Van Strien, T., Herman, C. P., Engels, R. C. M. E., Larsen, J. K., \& Van Leeuwe, J. F. J. (2007). Construct validation of the Restraint Scale in normal-weight and overweight females. Appetite, 49, 109-121.

Weiskopf, N., Hutton, C., Josephs, O., Turner, R., \& Deichmann, R. (2007). Optimized EPI for fMRI studies of the orbitofrontal cortex. Compensation of susceptibilityinduced gradients in the readout direction. Magma (New York, N.Y.), 20, 39-49.

Williamson, D. A., Martin, C. K., York-Crowe, E., Anton, S. D., Redman, L. M., Han, H., et al. (2007). Measurement of dietary restraint. Validity tests of four questionnaires. Appetite, 48, 183-192.

Yokum, S., Ng, J., \& Stice, E. (2011). Attentional bias to food images associated with elevated weight and future weight gain. An fMRI Study. Obesity, 19, 1775-1783.

Yokum, S., Ng, J., \& Stice, E. (2012). Relation of regional gray and white matter volumes to current BMI and future increases in BMI. A prospective MRI study. International Journal of Obesity (2005), 1-9. 